\title{
Lumbar herniated disc - endoscopic discectomy treatment
}

\author{
Author: Brazilian Society of Neurosurgery \\ Participants: Andrei Fernandes Joaquim²; Ricardo Vieira Botelho'; Marcelo Luis Mudo; \\ Antonio Silvinato de Almeida²; Wanderley Marques Bernardo (D1
}

Final version: December 10, 2016

1. Brazilian Medical Association, São Paulo, SP, Brasil 2. Brazilian Society of Neurosurgery, São Paulo, SP, Brasil

http://dx.doi.org/10.1590/1806-9282.64.05.397

The Guidelines Project, an initiative of the Brazilian Medical Association, aims to combine information from the medical field in order to standardize producers to assist the reasoning and decision-making of doctors.

The information provided through this project must be assessed and criticized by the physician responsible for the conduct that will be adopted, depending on the conditions and the clinical status of each patient.

\section{METHODOLOGY FOR EVIDENCE COLLECTION}

This guideline followed the pattern of a systematic review with evidence collection based on the movement of Evidence-Based Medicine, in which clinical experience is integrated with the ability of critical analysis, rationally applying scientific information, thus improving the quality of medical assistance.

We used the structured version of the question synthesized by the P.I.C.O. acronym, in which $\mathbf{P}$ stands for patients with a lumbar herniated disc with surgical indication; I for endoscopic lumbar discectomy intervention; $\mathbf{C}$ for comparison between microdiscectomy and open discectomy; and $\mathrm{O}$ for the outcomes related to the clinical effectiveness and safety. From the structured question, we identified the keywords used as a basis for the evidence search in the sources of data: Medline-PubMed (886 papers) and, after we applied the eligibility criteria (inclusion and exclusion), 25 papers were selected to answer the clinical questions (Appendix I).

\section{CLINICAL QUESTION}

Is endoscopic lumbar discectomy effective and safe when compared with microdiscectomy and open discectomy for patients with lumbar herniated disc and nerve compression or severe persistent symptoms who did not respond to conservative treatment?
Grades for recommendation and levels of evidence:

A: Experimental or observational studies of higher consistency.

B: Experimental or observational studies of lower consistency.

C: Uncontrolled case/study reports.

D: Opinion deprived of critical evaluation, based on consensus, physiological studies or animal models.

\section{OBJECTIVE:}

To identify the best evidence currently available related to the use of endoscopic lumbar discectomy as a treatment for lumbar herniated discs.

\section{CONFLICT OF INTEREST:}

No conflict of interest was declared by the participants in the preparation of this guideline.

\section{INTRODUCTION}

Lumbar herniated discs occur when the nucleus pulposus of an intervertebral disc protrudes through a rupture in the fibrous ring surrounding it. Its symptoms include lumbar or lower limb pain, accompanied by numbness and weakness. Permanent severe neurological damages, including foot drop, bladder dysfunc- 
tion, and cauda equina syndrome may sometimes occur. Lumbar discectomy is considered when there is no serious nerve compression or persistent symptoms that did not respond to conventional treatment. The surgical techniques include open discectomy, microdiscectomy, or minimally-invasive alternatives, using percutaneous endoscopic approaches. The choice of surgical procedure can be influenced by several factors, including the symptoms and signs presented, in addition to the location and size of the prolapsed disc. The full-endoscopic discectomy (ED) is a new type of minimally invasive surgery developed to reduce surgical trauma, accelerate postoperative recovery and maintain the integrity of the normal anatomy of the spinal column ${ }^{1,2}$. The terminology varies quite a lot, with several names to indicate the same procedure, with minimal changes. ED includes two different approaches, basically, with distinct indications and techniques: the transforaminal and the interlaminar ${ }^{3}$.

\section{RESULTS OF THE SELECTED EVIDENCE}

Patients with lumbar herniated disc confirmed by clinical symptoms and imaging exams (X-ray and MRI) were randomized into two groups: transforaminal percutaneous endoscopic lumbar discectomy (TPELD) and conventional fenestration discectomy (FD). The exclusion criteria were: (1) LHD associated to other diseases, including neuropathy, metabolic diseases, any heart, lung, liver, or kidney related diseases, or chronic/acute inflammation; (2) multilevel disc herniations; (3) spinal column infections, tumors, discitis or spinal tuberculosis; (4) recurrent disc herniation; and (5) lumbar instability or spondylolisthesis in more than two levels. A total of 48 patients were included in the TPELD group and 58 in the FD group, with an average follow-up time of 16.7 months $(12-25)$ e $17.3(12.5-23.5)$, respectively for each group. In the TPELD group, compared to the FD group, we found lower blood loss (in ml, $13.8 \pm 3.6$ vs $87.2 \pm 32.3 ; \mathrm{MD}=-74$; CI95\% -83.2 to $-64.8 ; \mathrm{p}<0.01$ ), shorter hospitalization time (days, $7.2 \pm 1.6$ vs $12.8 \pm$ $3.8 ; \mathrm{MD}=-5$; CI95\% -5.8 to $-4.10 ; \mathrm{p}<0.01)$, lower risk of complications (ARR = 0.14; CI95\% 0.019 to 0.269; NNT $=7$, CI95\% 4 to 52) in 6 months after the surgery. In TPELD, in comparison with FD, the pain was reduced (VAS) on the legs $(\mathrm{p}<0.05)$ and lumbar spine $(p<0.05)$, at the 6-month analysis; however, there was no difference for these comparisons at 12 months. As for the postoperative ODI score, there was no differ- ence between both groups at 6 and 12 months of followOup (all $\mathrm{p}<0.05$ ). Based on the modified MacNab, at the end of the follow-up, $95.84 \%$ of the patients in the TPELD group and $94.82 \%$ in the FD group were classified as excellent or good, with no significant difference between both groups $(p>0.05){ }^{4}(\mathbf{B})$ (This RCT is not included in the RSs mentioned here.)

A total of 1,092 adult patients ( $<70$ years) with symptomatic lumbar herniation was included in a systematic review with a meta-analysis that compared endoscopic discectomy (ED) and open discectomy (OD). Out of the 15 studies assessed in its integrity (search from August 2014), 9 RCTs with sample size ranging from 40 to 240 patients were meta-analyzed. Studies that included patients with acute vertebral fracture, infection, tumor, or rheumatoid arthritis were excluded. The studies included in the meta-analysis were heterogeneous in patient selection, surgery techniques, instruments used, and follow-up time (minimum of 1 year and loss $<20 \%$ for all studies). The authors observed that the studies had good methodological quality. The instrument used to measure clinical outcomes (primary outcome) was the MacNab criteria ("global perceived effect" or "global improvement"). There is no reference to the instrument used to assess the "patient satisfaction", considered a secondary outcome along with intraoperative blood loss and length of hospital stay. ${ }^{5}(\mathbf{B})$

The meta-analysis of the 9 RCTs showed the results below. ${ }^{5}(\mathbf{B})$

EFFECTIVENESS - There was no difference with statistical significance (ED vs OD)

- in the "global improvement" (MacNab criteria) between the ED (95.7\%) and OD (80\%), (3 studies, $\mathrm{n}=165$, OR $=3.72$, CI95\% [0.76 to 18.14], $\mathrm{p}=$ $0.10, \mathrm{I}^{2}=62 \%$ ).

- in the comparison of recurrence between ED $(5.04 \%)$ and $\mathrm{OD}(3.35 \%)$, [7 studies; $\mathrm{n}=417 ; \mathrm{OR}=$ 1.62; CI95\% [0.84, 3.12]; $p=0.15, \mathrm{I}^{2}=0 \%$;

- in the comparison of reoperation rates between ED (6.82\%) and OD (6.93\%), [8 studies; $n=440$; $\left.\mathrm{OR}=0,98, \mathrm{CI} 95 \%[0.60,1.61] ; \mathrm{p}=0.93, \mathrm{I}^{2}=0 \%\right]$

There was a difference with statistical significance (ED vs OD)

- in the proportion of satisfied patients (does not specify the evaluation instrument), being $93.2 \%$ in the ED group and $86.5 \%$ in the OD, (4 studies; $\mathrm{n}=221 ; \mathrm{OR}=2.19$, CI95\% [1.09 to 4.40]; $\mathrm{p}=0.03$, $\mathrm{I}^{2}=0 \%$;

- in the volume of intraoperative blood loss, fa- 
voring ED (3 studies; $\mathrm{n}=190 ; \mathrm{WMD}$ : -123.71 , CI95\% [-173.47, -73.95], p<0.00001, $\left.\mathrm{I}^{2}=99 \%\right)$;

- in the length of hospital stay, favoring ED (4 studies; $\mathrm{n}=220$; WMD: -144.45 , CI95\% [-239.54 to -49.37 ], $\left.\mathrm{p}=0.003, \mathrm{I}^{2}=99 \%\right)$

SAFETY - There was no difference with statistical significance (ED vs OD)

- in the comparison of complication rates, $\mathrm{Ed}$ (16.11\%) vs OD (20.12\%), [8 studies; $\mathrm{n}=447$; OR $=0.73, \mathrm{CI} 95 \%$ (0.34 a 1.57); $\left.\mathrm{p}=0.41, \mathrm{I}^{2}=75 \%\right)$.

The high heterogeneity $\left(\mathrm{I}^{2}\right)$ between the studies, in the analysis of the outcomes evaluated in this meta-analysis, affects some results. ${ }^{5}(\mathbf{B})$

This systematic review of RCTs compared microendoscopic discectomy (MED) with open discectomy (OD) or microdiscectomy (MD), evaluating their effectiveness and safety in patients with symptomatic lumbar herniated disc. Out of the 109 studies analyzed, the authors found only four randomized clinical trials that met the eligibility criteria (Huang et al. ${ }^{7}$, Righesso et al. ${ }^{8}$, Teli et al. ${ }^{9}$ and Garg et al. ${ }^{10}$ ) and reported the Oswestry Disability Index (ODI) as a result. Three studies compared MED and OD, and one compared OD, MD and MED (three groups). The eligibility criteria were studies that included adult patients with symptoms of sciatic pain, who did not respond to conventional treatment and with no previous lumbar herniated disc surgery. Endoscopic surgery by any method of MED that involved the use of an endoscopic tool was considered a surgical intervention, as well as the comparison between any OD and MD method. All four studies showed significant methodological flaws, especially referring to the low score in the CONSORT questionnaire. No significant differences were observed in the results between conventional microdiscectomy and endoscopic discectomy in the Oswestry Disability Index (ODI) scores in any period of time, thus showing similar effectiveness. However, Teli et al. ${ }^{9}$ reported a higher rate of complications in patients who underwent endoscopic discectomy. That study, obviously, has a profound impact on this analysis, being one of the largest randomized series reported (total $\mathrm{N}=$ 212). ${ }^{6}(\mathbf{B})$

A total of 8,396 adult patients with symptomatic lumbar herniated disc (39 studies reported in 45 articles) was included in this review, with search until 2008; being six prospective controlled studies (one RCT and five non-randomized; $n=920$ [412 transforaminal percutaneous endoscopic lumbar discecto- my (TPELD) versus 508 controls]), two retrospective controlled studies ( $\mathrm{n}=962$ [325 transforaminal percutaneous endoscopic lumbar discectomy versus 637 controls] and 31 before and after studies $(\mathrm{n}=6.514)$. The inclusion and exclusion criteria varied between the studies (often not clearly described). Thirty-six studies specified radiculopathy in inclusion criteria. In most studies, the patients received some kind of conservative preoperative treatment for a few months. The duration of symptoms varied; some included all types of hernia and other just some specific types. Therefore, several techniques were used (including intradiscal and intracanal), as well as different instruments. The follow-up time ranged from six weeks to 108 months. Sixteen studies had an average follow-up of over two years. The studies included in this review were heterogeneous in patient selection, surgical indication, surgery techniques, follow-up time and outcome measures. The authors observed that the studies had poor methodological quality. The studies used different instruments (validated and not validated) to measure the results. Pain was measured by the Visual Analog Scale (VAS) or visual numeric scale. The functional status was measured by the Oswestry Disability Index (ODI) or Roland Morris Disability Scale. The ODI measures the degree of disability in a person with lumbar pain. The index score ranges from 0 to 100, 0 indicating no disability and 100 maximum disability. The "global perceived effect" was measured using the MacNab score or the percentage of patients with improvement. Patient satisfaction was generally reported using a Likert scale. In two series of cases included, the intervention was the "endoscopic laser foraminoplasty" ( $n=250)$. None of the studies included was designed to assess adverse events. ${ }^{11}(\mathbf{B})$

A review of the eight studies with a control group showed the results below. ${ }^{11}(\mathbf{B})$

EFFECTIVENESS - There was no difference with statistical significance

- in the reduction of leg pain (VAS) between the group of transforaminal endoscopic surgery (89\%) and the open microdiscectomy group (87\%), (1 study, $\mathrm{n}=200)$;

- in the median score of "global improvement" (MacNab criteria) between transforaminal endoscopic surgery and open lumbar microdiscectomy (84\% versus $78 \%$ satisfactory, 5 studies, $\mathrm{n}$ $=1,102)$. The sum of the "excellent" and "good" 
scores were reported as "satisfactory";

- the median rates of recurrence between transforaminal endoscopic surgery (5.7\%) and open lumbar microdiscectomy $(2.9 \% ; 4$ studies, $\mathrm{n}=$ $1,182)$;

- in the median rates of reoperation between transforaminal endoscopic surgery $(6.8 \%)$ and open lumbar microdiscectomy (4.7\%; 6 studies, $\mathrm{n}=1,302)$. The most common cause of reoperation was the persistence of symptoms due to unresolved lateral stenosis and remaining fragments;

SAFETY - There was no difference with statistical significance

- in the median rates of complications between transforaminal endoscopic surgery $(1.5 \%)$ and open lumbar microdiscectomy (1.0\%; 6 studies, $\mathrm{n}=1,302)$. The most reported complications were transient dysesthesia or hypoesthesia.

The results of TPELD (effectiveness and safety) in 31 "before and after studies" included in this review are listed below with the results in median \% (max$\min ) .{ }^{11}(\mathbf{B})$

\section{EFFECTIVENESS OF TPELD}

- leg pain (VAS) - an improvement of 88\% (65\%89\%) - 7 studies, $\mathrm{n}=1558$,

- lumbar pain (VAS) - an improvement of $74 \%$ (13\%-84\%) - 5 studies, $\mathrm{n}=1401$,

- "global improvement" (MacNab criteria) - an improvement of $85 \%$ (72\%-94\%) - 15 studies (n = 2,544),

- functional state (ODI) - an improvement of $83 \%$ (74\%-90\%) - 3 studies, $\mathrm{n}=624$,

- returned to work - $90 \%$ (67\%-95\%) - 5 studies, $n$ $=757$,

- median rate of recurrence - $1.7 \%(0 \%-12 \%)$ - 13 studies, $\mathrm{n}=2,612$,

- median rate of reoperation - 7\% (0-27\%) - 28 studies $(\mathrm{n}=4.135)$.

SAFETY OF TPELD

- median rate complications - $2.8 \%(0 \%-40 \%)-28$ studies, $\mathrm{n}=6,336$,

This study concluded that the results on the effectiveness of transforaminal endoscopic surgery were poor and did not provide valid information to support or refute its use in patients with a symptomatic lumbar herniated disc. ${ }^{11}(\mathbf{B})$

This systematic review assessed the effectiveness and safety of the percutaneous endoscopic lumbar discectomy (PELD) in the treatment of recurrent lumbar herniated discs (rLHD), second surgery. Three controlled studies were included (an RCT, one non-randomized CT and a retrospective cohort), in addition to five studies with no control group (before and after [2] and observational retrospective [3]), with searches in publications from 2002 to July 2015. Patients with recurrence confirmed by imaging exams with the failure of the conservative treatment and a pain-free interval of six weeks were included in the studies. The main exclusion criteria for PELD were: sequestrated or calcified discs, lumbar stenosis greater than moderate, instability of the spinal column, spondylolisthesis, cauda equina syndrome, and severe neurological deficit. The methodological rigor and scientific quality of the studies were considered in the analysis and conclusion of this review. In order to compare PELD and open discectomy (OD), a meta-analysis was carried out, including the three controlled studies, whose quality was considered high after the analysis. The quality of the five non-controlled studies was considered moderate/high. ${ }^{12}(\mathbf{B})$

An assessment of the eight studies $(n=475$; three controlled and five non-controlled ) included in this review showed the following results, expressed in mean and range (min-max). ${ }^{12}(\mathbf{B})$

PELD without comparison with a control group with a follow-up time ranging from 13 to 42 months, approximately:

\section{EFFECTIVENESS}

leg pain improvement (VAS) of $66.92 \%$ (50.6\%89.87\%), 7 studies $(\mathrm{n}=457)$,

back pain improvement (VAS) of 54.91\% (29\%67.95\%), 5 studies ( $\mathrm{n}=339$ ),

improvement in the McNab score/patient satisfaction percentage of $75.77 \%$ (60\%-95\%), 5 studies (n $=391$,

- functional state improvement (ODI) of $60.9 \%$ (40.7\%-75\%), 4 studies $(\mathrm{n}=111)$,

- presented a rate of recurrence of $6.3 \%$ (4\%-10\%) assessed in 6 studies $(\mathrm{n}=414)$,

- presented a rate of reoperation of $3.66 \%$ (2.33\%$4.8 \%), 3$ studies, $(\mathrm{n}=110)$

SAFETY

- the global average of the rate of complications was $4.89 \%(0 \%-9,76 \%)$,

- the rate of dural tears was of $0.1 \%(0 \%-4.9 \%)$.

A meta-analysis including the three studies with a control group, with a total of 197 patients (93 PELD versus $104 \mathrm{OD}$ ), presented the results below. ${ }^{12}$ (B)

PELD compared with OD (result in mean differ- 
ence), with a follow-up time that ranged from 24 to 34 months between the studies:

\section{EFFECTIVENESS}

- reduced surgical time (3 studies [n $=197,68$ PELD vs 65 OD]; DM $=-59.08$, CI95\% -98.03 $-20.13 ; p=0.003)$, but with significant heterogeneity among the studies $\left(\mathrm{I}^{2}=94 \%, \mathrm{p}<0.00001\right)$,

- there was no difference in intraoperative bleeding (ml) (2 studies [ $\mathrm{n}=143$; 68 PELD vs 75 OD]; $(\mathrm{DM}=-161.73$, CI95\% -418.46 to 95.01, $\mathrm{p}=0.22)$; significant heterogeneity among the studies $\left(\mathrm{I}^{2}\right.$ $=96 \%, \mathrm{p}=0.0001$ ),

- there was no difference in length (days) of hospital stay (2 studies [n = 97; 43 PELD vs 54 D], $\mathrm{DM}=-6.49$, CI95\% -13.83 to $0.84, \mathrm{p}=0.08$ ), with significant heterogeneity among the studies $\left(\mathrm{I}^{2}\right.$ $=96 \%, \mathrm{p}<0.00001$ ),

- there was no difference in leg pain reduction (VAS) (3 studies [ $\mathrm{n}=184 ; 88$ PELD vs 96 OD], DM $=2.03$, CI95\% -1.38 a 5.44, $\mathrm{p}=0.24)$; significant heterogeneity among the studies $\left(\mathrm{I}^{2}=80 \%, \mathrm{p}=\right.$ 0.007),

- there was no difference in lumbar pain reduction (VAS) (2 studies [ $\mathrm{n}=141 ; 70$ PELD vs 71 OD], $\mathrm{DM}=-0.28$, CI95\% -3.90 a 3.33, $\mathrm{p}=0.88$ ); with significant heterogeneity among the studies $\left(\mathrm{I}^{2}\right.$ $=91 \%, \mathrm{p}<0.00007$ ),

- there was no difference in functional state (ODI), [2 studies, $\mathrm{n}=141$; 70 PELD vs 71 OD], DM $=-3.62$, CI95\% -13.93 a $6.70, p=0.49$ ); with no heterogeneity among these studies $\left(\mathrm{I}^{2}=0 \%, \mathrm{p}=\right.$ 0.92),

- there was no difference in recurrence risk (3 studies, $\mathrm{n}=184$; 85 PELD vs 99 OD), $\mathrm{RR}=0.53$, CI95\% 0.13 a 2.22, $\mathrm{p}=0.39$ ), with no heterogeneity among these studies $\left(I^{2}=0 \%, p=0.66\right)$.

SAFETY - PELD versus OD

- there was no difference in risk of infection of the surgical wound, $\mathrm{RR}=0.38, \mathrm{CI} 95 \% 0.06 \mathrm{a}$ $2.45 ; p=0.31$; with no heterogeneity among the studies, $\mathrm{I}^{2}=0 \%$.

- there was no difference in risk of dural tears, $\mathrm{RR}=0.27$, CI95\% 0.06 a 1.30; $\mathrm{p}=0.10$; with no heterogeneity among the studies, $\mathrm{I} 2=0 \%$,

- reduced the risk of complications considered serious in this study (surgical wound infection, dural tear, damage to nerve roots, cauda equina syndrome, cerebrospinal fluid fistula, transient dysesthesia of the leg $(\mathrm{RR}=0.24$, CI95\% 0.08 to $0.71, \mathrm{p}=0.01$ ); composite outcome.12(B)

\section{DISCUSSION}

The results of this review showed that the bleeding and length of hospital stay were lower with the percutaneous lumbar discectomy in comparison with MD/OD. The differences were small and did not reach the standard threshold for clinically significant differences in the assessment of outcomes, such as: global improvement (McNab criteria), function improvement (Oswestry Disability Index), recurrences, reoperations, and complications (clinical outcomes). A RCT (Teli et al. ${ }^{9}$ ) included in a systematic review (Smith et al. ${ }^{6}$ ) and, therefore, not separately described in this review, showed an increase in the number of complications; however, another RCT (Pan Z et al. ${ }^{4}$ ) showed a reduction. Another study that showed a decrease in the number of complications assessed the composite outcome and, when the analysis was carried out separately, by outcome (infection and dural tears), it did not find any differences..$^{12}(\mathbf{B})$

It is important to consider that this review grouped different surgical and instrumental techniques, according to the type of lumbar disc herniation. For this review, the results of the meta-analysis with high heterogeneity $\left(\mathrm{I}^{2}>80 \%\right)$ were not considered consistent. The analysis was deemed to be consistent when it had low heterogeneity $\left(\mathrm{R}^{2}=0 \%\right)$ for the outcomes: recurrence, reoperation, improvement in functional status. The general opinion of the authors, reported in the discussion/conclusion sections of most studies, is that the results for endoscopic microdiscectomy are comparable to that of a standard microdiscectomy.

\section{RECOMMENDATION}

For patients with lumbar herniated disc (recurrent or not) and surgical indication, the endoscopic lumbar discectomy, when compared with the microdiscectomy or open discectomy:

- had similar results in "global improvement" (MacNab criteria), functional status (Oswestry Disability Index), leg pain (VAS), lumbar pain (VAS), recurrence, reoperation and complications.

- reduced the bleeding (in $\mathrm{ml}, \mathrm{MD}=-74$, CI95\% -83.2 To $-64.8, p<0.01$ ), and the length of hospital stay (in days, $\mathrm{MD}=-5$, CI95\% -5.8 to -4.10 , $\mathrm{p}<0.01)$.

STRONG RECOMMENDATION GRADE / MODERATE LEVEL OF EVIDENCE (GRADE 1B) 


\section{REFERENCES}

1. Ruetten S, Komp M, Merk H, Godolias G. A new full-endoscopic technique for cervical posterior foraminotomy in the treatment of lateral disc herniations using 6.9-mm endoscopes: prospective 2-year results of 87 patients. Minim Invasive Neurosurg 2007; 50:219-26. PMID: 17948181

2. Birkenmaier C, Komp M, Leu HF, Wegener B, Ruetten S. The current state of endoscopic disc surgery: review of controlled studies comparing full-endoscopic procedures for disc herniations to standard procedures. Pain Physician 2013 ; 16:335-44. PMID: 23877449

3. Choi KC, Kim JS, Ryu KS, Kang BU, Ahn Y, Lee SH. Percutaneous endoscopic lumbar discectomy for L5-S1 disc herniation: transforaminal versus interlaminar approach. Pain Physician 2013;16:547-56. PMID: 24284840

4. Pan Z, Ha Y, Yi S, Cao K. Efficacy of Transforaminal Endoscopic Spine System (TESSYS) Technique in Treating Lumbar Disc Herniation. Med Sci Monit 2016 18;22:530-9. PMID: 26887645

5. Cong L, Zhu Y, Tu G. A meta-analysis of endoscopic discectomy versus open discectomy for symptomatic lumbar disk herniation. Eur Spine 2016; 25:134-43. PMID: 25632840

6. Smith N, Masters J, Jensen C, Khan A, Sprowson A. Systematic review of microendoscopic discectomy for lumbar disc herniation. Eur Spine J 2013; 22:2458-65. PMID: 23793558

7. Huang TI, Hsu RW, Li YY, Cheng CC. Less systemic cytokine response in patients following microendoscopic versus open lumbar discectomy. I Orthop Res 2005; 23:406-11. PMID: 15734255

8. Righesso O, Falavigna A, Avanzi O. Comparison of open discectomy with microendoscopic discectomy in lumbar disc herniations: results of a randomized controlled trial. Neurosurgery. 2007; 61:545-9; discussion 549. PMID: 17881967

9. Teli M, Lovi A, Brayda-Bruno M, Zagra A, Corriero A, Giudici F, Minoia L. Higher risk of dural tears and recurrent herniation with lumbar micro-endoscopic discectomy. Eur Spine J. 2010; 19:443-50. PMID: 20127495

10. Garg B, Nagraja UB, Jayaswal A. Microendoscopic versus open discectomy for lumbar disc herniation: a prospective randomised study. I Orthop Surg (Hong Kong) 2011;19:30-4. PMID: 21519072

11. Nellensteijn J, Ostelo R, Bartels R, Peul W, van Royen B, van Tulder M Transforaminal endoscopic surgery for symptomatic lumbar disc herniations: a systematic review of the literature. Eur Spine | 2010; 19:181-204. PMID: 19756781

12. Li X, Hu Z, Cui J, Han Y, Pan J, Yang M, Tan J, Sun G, Li L. Percutaneous endoscopic lumbar discectomy for recurrent lumbar disc herniation. Int Surg 2016; 27:8-16. PMID: 26805569

13. Shea BI, Hamel C, Wells GA, Bouter LM, Kristjansson E, Grimshaw | et al. AMSTAR is a reliable and valid measurement tool to assess the methodological quality of systematic reviews. I Clin Epidemiol 2009; 62:1013-20. PMID: 19230606 (http://amstar.ca/Amstar_Checklist.php)

14. Jadad AR, Moore RA, Carroll D, Jenkinson C, Reynolds DJ, Gavaghan DJ, et al. Assessing the quality of reports of randomized clinical trials: is blinding necessary? Control Clin Trials 1996; 17:1-12.
15. Guyatt G, Gutterman D, Baumann MH, Addrizzo-Harris D, Hylek EM, Phillips B et al. Grading strength of recommendations and quality of evidence in clinical guidelines: report from an american college of chest physicians task force. Chest 2006;129(1):174-81. PMID: 16424429

16. Levels of Evidence and Grades of Recommendations - Oxford Centre for Evidence Based Medicine. Disponível em URL: http://cebm.jr2.ox.ac.uk/ docs/old_levels.htm.

17. Anichini G, Landi A, Caporlingua F, Beer-Furlan A, Brogna C, Delfini R et al. Lumbar Endoscopic Microdiscectomy: Where Are We Now? An Updated Literature Review Focused on Clinical Outcome, Complications, and Rate of Recurrence. Biomed Res Int 2015; 2015:417801. PMID: 26688809

18. Lee DY, Shim CS, Ahn Y, Choi YG, Kim HJ, Lee SH. Comparison of percutaneous endoscopic lumbar discectomy and open lumbar microdiscectomy for recurrent disc herniation. J Korean Neurosurg Soc 2009; 46:515-21. PMID: 20062565

19. Birkenmaier C, Komp M, Leu HF, Wegener B, Ruetten S. The current state of endoscopic disc surgery: review of controlled studies comparing full-endoscopic procedures for disc herniations to standard procedures. Pain Physician 2013;16:335 44. PMID: 23877449

20. Hussein M, Abdeldayem A, Mattar MM. Surgical technique and effectiveness of microendoscopic discectomy for large uncontained lumbar disc herniations: a prospective, randomized, controlled study with 8 years of follow-up. Eur Spine J 2014;23:1992-9. PMID: 24736930

21. Li XC, Zhong CF, Deng GB, Liang RW, Huang CM. Full-Endoscopic Procedures Versus Traditional Discectomy Surgery for Discectomy: A Systematic Review and Meta-analysis of Current Global Clinical Trials. Pain Physician 2016;19:103-18. PMID: 27008284

22. Pan L, Zhang P, Yin Q. Comparison of tissue damages caused by endoscopic lumbar discectomy and traditional lumbar discectomy: a randomised controlled trial. Int | Surg 2014;12:534-7. PMID: 24583364

22. Rasouli MR, Rahimi-Movaghar V, Shokraneh F, Moradi-Lakeh M, Chou R. Minimally invasive discectomy versus microdiscectomy/open discectomy for symptomatic lumbar disc herniation. Cochrane Database Syst Rev 2014; 9:CD010328. PMID: 25184502

23. Ruetten S, Komp M, Merk H, Godolias G. Full-endoscopic interlaminar and transforaminal lumbar discectomy versus conventional microsurgical technique: a prospective, randomized, controlled study. Spine (Phila $\mathrm{Pa}$ 1976) 2008; 33:931-9. PMID: 18427312

24. Ruetten S, Komp M, Merk H, Godolias G. Full-endoscopic anterior decompression versus conventional anterior decompression and fusion in cervical disc herniations. Int Orthop 2009;33:1677-82. PMID: 19015851

25. Ruetten $\mathrm{S}$, Komp M, Merk H, Godolias G. Recurrent lumbar disc herniation after conventional discectomy: a prospective, randomized study comparing full-endoscopic interlaminar and transforaminal versus microsurgical revision. I Spinal Disord Tech 2009; 22:122-9. PMID: 19342934

26. Ruan W, Feng F, Liu Z, Xie J, Cai L, Ping A. Comparison of percutaneous endoscopic lumbar discectomy versus open lumbar microdiscectomy for lumbar disc herniation: A meta-analysis. Int J Surg 2016; 31:86-92. PMID: 27260312 


\section{APPENDIX I}

\section{Clinical question}

Is endoscopic lumbar discectomy effective and safe when compared with microdiscectomy and open discectomy for patients with lumbar herniated disc and surgical indication?

\section{Structured question}

P - Patients with a lumbar herniated disc with surgical indication

I - Endoscopic lumbar discectomy

C - Microdiscectomy or open discectomy

O - Outcomes related to clinical effectiveness and safety

\section{Methodology for evidence search \\ PubMed-Medline}

\#1 - (Intervertebral Disk Displacement OR Disc, Herniated OR Discs, Herniated OR Disk, Herniated OR Disks, Herniated) AND (Surgical Procedures, Endoscopic OR Surgical Procedure, Endoscopic OR Surgical Endoscopy OR Endoscopy OR endoscopic OR Percutaneous Endoscopic Discectomy OR endoscopic discectomy)

\#2 - (Diskectomies OR Discectomy OR Discectomies OR Diskectomy) AND (Surgical Procedures, Endoscopic OR Surgical Procedure, Endoscopic OR Surgical Endoscopy OR Endoscopy OR Percutaneous Endoscopic Discectomy OR endoscopic discectomy)

\#1 OR \#2

\section{Cochrane Library}

disc herniation AND discectomy

\section{Returned studies}

The literature review was carried out until December 10, 2016 in the databases Medline/PubMed and Cochrane Library. The studies were identified in terms of MeSH vocabulary and free text (Table 1).

The evidence used was retrieved by the following steps: elaboration of the clinical question, structuring of the question, search for evidence, presentation of results, and recommendations.

TABLE 1 - NO. OF PAPERS RETURNED FROM THE SEARCH METHODOLOGY USED IN EACH OF THE SCIENTIFIC DATABASES

\begin{tabular}{|l|l|}
\hline DATABASE & NUMBER OF PAPERS \\
\hline Medline/PubMed & $\mathbf{8 8 6}$ \\
\hline Cochrane Library & $\mathbf{1 7 4}$ \\
\hline
\end{tabular}

\section{Inclusion criteria for the selected papers}

The selection of the studies and the evaluation of the titles and abstracts obtained from the search strategy in the databases consulted were independently and blindly conducted by two researchers with expertise in the development of systematic reviews, in total accordance with the inclusion and exclusion criteria established and described in the PICO. Finally, the studies with potential relevance were separated.

\subsection{According to the designs of the studies}

Systematic Reviews (SRs) were included, with or without meta-analysis that did not include the same studies, and RCTs published $a$ posteriori.

The evidence retrieved was selected based on a critical assessment that used the Amstar (A Measurement Tool to Assess Reviews) tool for SRs and the Jadad $^{14}$ and Grade ${ }^{15}$ discriminatory instruments (scores) for the RCTs.

The Type II Error was not used in the selection of RCTs in order to avoid greater limitation.

\subsection{Language}

Studies available in Portuguese, English, Italian or Spanish were included.

\subsection{According to the publication}

Only studies with texts available in its entirety were considered for critical evaluation.

\section{Method for critical evaluation}

From the databases, after the initial critical evaluation, were selected: Medline/PubMed (5 studies), Cochrane Library (0) (Appendix II).

The papers considered for complete reading were critically evaluated following the inclusion and exclusion criteria, based on study performance, PICO, language and availability of the text in its entirety.

Out of the five papers considered for critical evaluation, none was excluded for not being complete.

Amstar ${ }^{13}$ was used to evaluate the quality of the systematic reviews. This tool provides a global quality rating on a scale from 0 to 11 , in which 11 represents a review of the highest quality. Quality categories were determined as follows: low (0 to 3 score), medium (4 to 7 score) and high (8 to 11 score). SRs of low and medium quality were excluded (Appendix III)

When, after the inclusion and exclusion criteria 
were applied, the evidence selected was classified as Randomized Controlled Trial (RCT), it was subjected to a suitable critical evaluation check-list Table 2).

The critical evaluation of RCT allows to classify it according to the Jadad score ${ }^{14}$, considering Jadad trials $<3$ (three) as inconsistent, and those with score $\geq 3$ (three) consistent.

During the critical evaluation, the Grade ${ }^{15}$ (Grading of Recommendations Assessment, Development and Evaluation) discriminatory instrument was also applied, using evidence of high and moderate quality (Table 3).

TABLE 2 - GUIDE FOR CRITICAL EVALUATION OF RANDOMIZED CONTROLLED TRIALS

\begin{tabular}{|l|l|}
\hline $\begin{array}{l}\text { Study data } \\
\text { Reference, study design, level } \\
\text { of evidence }\end{array}$ & $\begin{array}{l}\text { Sample size calculation } \\
\text { Estimated differences, power, } \\
\text { significance level, the total } \\
\text { number of patients }\end{array}$ \\
\hline $\begin{array}{l}\text { Patient selection } \\
\text { Inclusion and exclusion criteria }\end{array}$ & $\begin{array}{l}\text { Patients } \\
\text { Recruited, randomized, } \\
\text { prognostic differences }\end{array}$ \\
\hline $\begin{array}{l}\text { Randomization } \\
\text { Description and blinded } \\
\text { allocation }\end{array}$ & $\begin{array}{l}\text { Patient follow-up } \\
\text { Time, losses, migration }\end{array}$ \\
\hline $\begin{array}{l}\text { Treatment protocol } \\
\text { Intervention, control, and } \\
\text { blinding }\end{array}$ & $\begin{array}{l}\text { Analysis } \\
\text { Intention to treat, analyzed } \\
\text { intervention and control }\end{array}$ \\
\hline $\begin{array}{l}\text { Outcomes considered } \\
\text { Primary, secondary, } \\
\text { measurement instrument for } \\
\text { the outcome of interest }\end{array}$ & $\begin{array}{l}\text { Results } \\
\text { Benefit or harm in absolute data } \\
\text { Survival analysis }\end{array}$ \\
\hline
\end{tabular}

Presentation of the results of the evidence selected

The results regarding the intervention considered in the clinical question will be exposed individually, by means of the following items: clinical question, number of selected works (according to the criteria of inclusion), main reasons for exclusion and synthesis of the evidence available.

References related to studies included and excluded will be arranged in the item References and the reasons for exclusion in Appendix IV.

For results with available evidence, the population, intervention, outcomes, presence or absence of benefits and/or harmful effects, and controversy will be specifically defined whenever possible.

Matters related to costs will not be included in the results, and the outcomes considered will be limited to the clinical effectiveness and safety of the interventions.

\section{Recommendations}

The recommendations will be elaborated by the authors of the review, with the initial characteristic of synthesis of evidence, and will subject to validation by all authors who participated in creating the Guideline.

The level of recommendation used comes directly from the power available in the studies included in Oxford $^{16}$ and the use of the Grade system ${ }^{15}$.

TABLE 3 - DESCRIPTIVE TABLE OF THE BIASES IN THERAPEUTIC STUDIES

\begin{tabular}{l|l|l|l|l|l|l|l|l|} 
STUDY & QUESTION & RANDOMIZATION & ALLOCATION & BLINDING & LOSSES & PROGNOSIS & OUTCOMES & ITT \\
\hline $\begin{array}{l}\text { Pan Z } \\
2016^{\mathbf{1 0}}\end{array}$ & $\begin{array}{l}\text { Yes. } \\
\text { Suitable }\end{array}$ & $\begin{array}{l}\text { There was ran- } \\
\text { domization, but no } \\
\text { description }\end{array}$ & No description & $\begin{array}{l}\text { Blinding of } \\
\text { the outcome } \\
\text { evaluator }\end{array}$ & $\begin{array}{l}\text { There was } \\
\text { none }\end{array}$ & $\begin{array}{l}\text { No difference } \\
\text { between the } \\
\text { groups }\end{array}$ & $\begin{array}{l}\text { Short follow-up } \\
\text { time. Adequate } \\
\text { scores }\end{array}$ & \begin{tabular}{l} 
No \\
\hline
\end{tabular}
\end{tabular}

ITT $=$ analysis by intention to treat $/ \mathrm{Jadad}=3 /$ Sample size calculation $=$ There was none 


\section{APPENDIX II}

Diagram of recovery and initial selection of papers

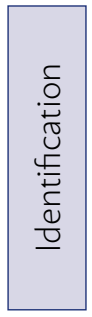

Papers identified in the Medline database $\operatorname{search}(n=886)$

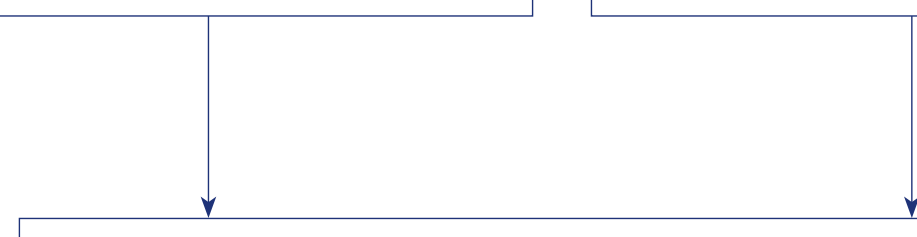

Papers after duplicates were excluded

$$
(n=846)
$$
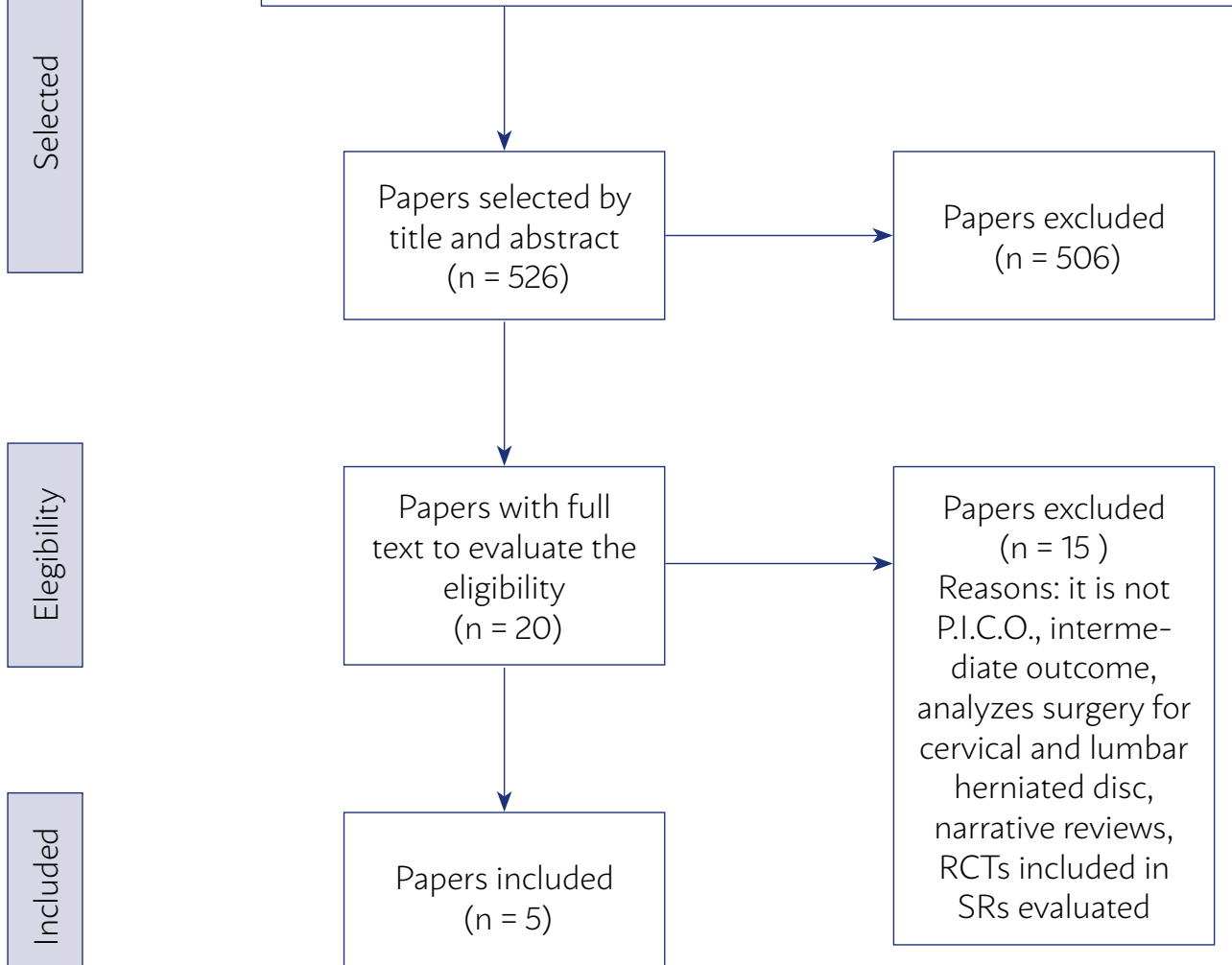


\section{APPENDIX III}

\section{Amstar (a measurement tool to assess reviews)}

\begin{tabular}{|c|c|c|c|c|}
\hline & $\begin{array}{l}\text { Cong L et al. } \\
\qquad(2016)^{5}\end{array}$ & $\begin{array}{l}\text { Smith N et al. } \\
\qquad(2013)^{6}\end{array}$ & $\begin{array}{l}\text { Nellensteijn J et } \\
\text { al. }(2010)^{11}\end{array}$ & $\begin{array}{l}\text { Li X et al. } \\
(2016)^{12}\end{array}$ \\
\hline Was a project received a priori? & Y & Y & Y & Y \\
\hline $\begin{array}{l}\text { Were there duplicates in the study selection and data } \\
\text { extraction? }\end{array}$ & Y & Y & Y & Y \\
\hline $\begin{array}{l}\text { Was a comprehensive bibliographic search/research } \\
\text { conducted? }\end{array}$ & Y & Y & Y & Y \\
\hline $\begin{array}{l}\text { Was the publication status (i.e., gray literature) used as an } \\
\text { inclusion criterion? }\end{array}$ & Y & Y & Y & Y \\
\hline Was a study list (included and excluded) provided? & $\begin{array}{c}\mathrm{N} \\
\text { (only included) }\end{array}$ & $\begin{array}{c}\mathrm{N} \\
\text { (only included) }\end{array}$ & $\begin{array}{c}\mathrm{N} \\
\text { (only included) }\end{array}$ & $\begin{array}{c}\mathrm{N} \\
\text { (only included) }\end{array}$ \\
\hline Were the characteristics of the studies provided? & Y & Y & Y & Y \\
\hline $\begin{array}{l}\text { Was the scientific quality of the studies included assessed and } \\
\text { documented? }\end{array}$ & Y & Y & Y & Y \\
\hline $\begin{array}{l}\text { Was the scientific quality of the studies included used properly } \\
\text { in formulating the conclusions? }\end{array}$ & Y & Y & Y & Y \\
\hline $\begin{array}{l}\text { Were the methods used to combine the studies results } \\
\text { appropriate? }\end{array}$ & Y & Y & Y & Y \\
\hline Was the probability of publication bias assessed? & Y & Y & Y & Y \\
\hline Were conflicts of interest informed? & Y & Y & Y & Y \\
\hline Total score & 10 & 10 & 10 & 10 \\
\hline
\end{tabular}

\section{APPENDIX IV}

\section{Studies excluded and the reason for exclusion}

\begin{tabular}{l|l} 
STUDY & REASON \\
\hline Anichini G 201517 & It is not a SR \\
\hline Lee DY 200918 & Included in meta-analysis evaluated \\
\hline Birkenmaier C 201319 & SR includes cervical and lumbar herniation \\
\hline Garg B 201110 & Included in SR evaluated \\
\hline Huang TI 20057 & Included in SR \\
\hline Hussein M 201420 & Included in SR \\
\hline Li XC 201621 & Includes cervical and lumbar \\
\hline Pan L 201422 & Intermediary outcome \\
\hline Rasouli MR 201423 & Partially answers PICO and more recent SRs include all its studies \\
\hline Righesso O 20078 & Included in SR evaluated \\
\hline Ruetten S 200824 & Included in SR evaluated \\
\hline Ruetten S 200925 & Does not answer to PICO (cervical hernia) \\
\hline Ruetten S 200926 & Included in SR evaluated \\
\hline Teli M9 & Included in SR evaluated \\
\hline Ruan W 201627 & Medium quality in Amstar \\
\hline
\end{tabular}




\section{APPENDIX V}

RESULTS - using studies that allow for the comparison of both procedures

\begin{tabular}{|c|c|c|c|c|c|c|c|c|c|c|}
\hline \multirow[t]{2}{*}{ STUDY } & \multirow{2}{*}{$\begin{array}{l}\text { TYPE OF } \\
\text { STUDY AND } \\
\text { POPULATION } \\
\text { INCLUDED } \\
\text { (N) }\end{array}$} & \multicolumn{9}{|c|}{$\begin{array}{l}\text { OUTCOMES - ENDOSCOPIC DISCECTOMY COMPARED } \\
\text { TO MICRODISCECTOMY OR OPEN DISCECTOMY }\end{array}$} \\
\hline & & $\begin{array}{c}\text { MacNab } \\
\text { Criteria }\end{array}$ & $\begin{array}{l}\text { Oswestry } \\
\text { Disability } \\
\text { Index }\end{array}$ & Leg pain & $\begin{array}{l}\text { Lumbar } \\
\text { pain }\end{array}$ & $\begin{array}{l}\text { Recur- } \\
\text { rence }\end{array}$ & $\begin{array}{l}\text { Reoper- } \\
\text { ation }\end{array}$ & Bleeding & $\begin{array}{l}\text { Length of } \\
\text { hospital } \\
\text { stay }\end{array}$ & $\begin{array}{l}\text { Complica- } \\
\text { tions }\end{array}$ \\
\hline Cong L $2016^{5}$ & $\begin{array}{l}\text { RS } \\
N=1.092\end{array}$ & ND & & & & ND & ND & । & । & ND \\
\hline Smith N20136 & $\begin{array}{l}\text { RS } \\
N=414\end{array}$ & & ND & & & & & & & \\
\hline $\begin{array}{l}\text { Nellensteijn J } \\
2010^{9}\end{array}$ & $\begin{array}{l}\text { RS } \\
N=8.396\end{array}$ & ND & & ND & & ND & ND & & & ND \\
\hline $\begin{array}{l}\text { Li X2016 } \\
\text { (Recurrent } \\
\text { lumbar herni- } \\
\text { ated disc - 2nd } \\
\text { surgery) }\end{array}$ & $\begin{array}{l}\mathrm{RS} \\
\mathrm{N}=579\end{array}$ & & ND & & & & & । & । & $\begin{array}{l}\text { B (for the } \\
\text { composite } \\
\text { outcome } \\
\text { - serious } \\
\text { compli- } \\
\text { cations) } \\
\text { ND = for } \\
\text { infection } \\
\text { of surgical } \\
\text { wound and } \\
\text { dural tear }\end{array}$ \\
\hline Pan Z $2016^{4}$ & $\begin{array}{l}\text { RCT } \\
N=106\end{array}$ & ND & ND & $\begin{array}{l}B \text { in } 6 M \\
N D \text { in } \\
12 M\end{array}$ & $\begin{array}{l}B \text { in } 6 M \\
N D \text { in } \\
12 M\end{array}$ & & & $\begin{array}{l}\text { B: in ml } \\
(M D=-74 \\
\text { C195\% } \\
-83.2 \mathrm{a} \\
-64.8) ; \\
p<0.01\end{array}$ & $\begin{array}{l}\text { B: in days } \\
(M D=-5 \\
\text { Cl95\% } \\
-5.8 a \\
-4.10) \\
p<0.01\end{array}$ & $\begin{array}{l}\text { B: in 6M } \\
\text { (NNT = } \\
7 \text { C195\% } \\
4-52\end{array}$ \\
\hline
\end{tabular}

$B=$ benefit favoring endoscopic discectomy, $D=$ damage with endoscopic discectomy, ND = no difference between procedures (ED vs OD), I = inconclusive due to the high heterogeneity of the meta-analysis $\left(I^{2}>80 \%\right)$, NNT = number needed to treat, $M=$ months, $D M=$ mean difference 